\title{
História, política e educação: \\ o novo modelo de escolarização primária em Moçambique
}

\author{
History, policy and education: \\ the new primary schooling model in Mozambique \\ Historia, política y educación: \\ el nuevo modelo de escuelar primario en Mozambique
}

OCTAVIO Jose ZIMBICO

Universidade Eduardo Mondlane, Maputo, Moçambique. $\diamond$

\begin{abstract}
RESUMO
Este texto trata do modelo de escolarização primária em Moçambique, de 1975 a 1982, partindo da questão: até que ponto as mudanças organizacionais afetaram esse modelo, ao nível das políticas educativas e das propostas paradigmáticas? A metodologia consistiu na revisão bibliográfica e análise da revista Tempo. Concluímos que a escola primária moçambicana é um modelo político, que, em termos organizacionais é centro democrático e de formação do homem novo ${ }^{1}$. Ao nível da política educativa era um modelo a replicar. Em termos de propostas paradigmáticas, as relações entre os sujeitos (alunos e professores) deviam se basear no nacionalismo e na emancipação.
\end{abstract}

Palavras-chave: Modelo escolar. Escola primária moçambicana. Espaço de debate.

\section{Abstract}

This text deals with the model of primary schooling in Mozambique, from 1975 to 1982, starting from the question: to what extent did organizational changes affect this model, in terms of educational policies and paradigmatic proposals? The methodology consisted of the bibliographical review and analysis of the Tempo Magazine. We conclude that the Mozambican primary school is a political model, which, in organizational terms, is a democratic and training center for the new man. At the level of educational policy was a model to replicate. In terms of paradigmatic proposals, the relations between the subjects (students and teachers) should be based on nationalism and emancipation.

Keywords: School model. Mozambican primary school. Discussion space.

\section{RESUMEN}

Este texto trata del modelo de escuelar primario en Mozambique, de 1975 a 1982, partiendo de la cuestión: hasta que punto los cambios organizacionales afectaron ese modelo, al nivel de las políticas educativas y de las propuestas paradigmáticas? La metodología consistió en el repaso bibliográfico y análisis de la Revista Tiempo. Concluimos que la escuela primaria mozambicana es un modelo político, que, en términos organizacionales, es centro democrático y de formación del hombre nuevo. Al nível de la política educativa era un modelo por replicar. En términos de propuestas paradigmáticas, las relaciones entre los sujetos (alumnos y profesores) debían basarse en el nacionalismo y liberación.

Palabras clave: Modelo escuelar. Escuela primaria mozambicana. Espacio de debate.

\footnotetext{
1 "Homem novo" era o modelo ideal do cidadão que o projeto socialista pretendia formar em Moçambique, ou seja, um cidadão emancipado, com elevada consciência patriótica, livre da mentalidade colonial.
} 


\section{INTRODUÇÃO}

O objetivo deste texto é analisar o processo de construção do modelo de escolarização primária idealizada para uma sociedade moçambicana pós-colonial, a partir dos debates veiculados pela revista Tempo, no período que vai da independência até a aprovação do Sistema Nacional de Educação (1975 a 1982). O primeiro diagnóstico que se fez, no setor da educação em Moçambique, logo após a independência do país (1975), apontou que o modelo de escolarização primária, concebido pelo regime colonial, não se ajustava à realidade da nova sociedade do país após a independência, era, então, necessário reverter o cenário educativo da época.

Nesse sentido, importantes encontros marcaram os momentos deste debate de definição do modelo de escolarização primária que se pensava ideal para formação do homem novo, para uma nova sociedade póscolonial. Esse debate, memorizado pela revista Tempo, resultou não só na definição do que deveria ser uma escola primária moçambicana, mas também na definição das ações a levar a cabo para sua implementação efetiva. Estas análises podem contribuir para renovação da história da escolarização primária em Moçambique, se pensarmos que para compreender a gênese do modelo de escolarização primária, aprovado pela Lei no 4/83, de 23 de março, é necessário um conhecimento dos debates nacionais que antecederam sua definição e serviram de base para a formulação das políticas educativas, suas respectivas estratégias de implementação.

A escolha da revista Tempo como fonte de localização deste debate educacional justifica-se pelo fato de primeiro, ela ter consistido em um veículo hegemônico de disseminação das ideologias do Estado e doutrinação das populações nesse período da construção da nova nação; segundo, porque ela acompanhou a evolução da escolarização em Moçambique, podendo ser considerada uma agência de análise dos problemas do sistema, capaz de orientar o pensamento educativo. A despeito da riqueza de registros sobre a época, ela tem sido pouco explorada no âmbito acadêmico, seja como objeto ou como fonte. Dentre os trabalhos que encontramos, consta um artigo científico publicado pela professora brasileira Jacimara Souza Santana (2009), intitulado "Mulheres de Moçambique na revista Tempo: o debate sobre o lobolo", e "A Participação das Mulheres na Luta de Libertação Nacional de Moçambique em Notícias (revista Tempo 1975-1985)", além da tese defendida por Octávio José Zimbico (2016), que usa a revista Tempo como fonte de pesquisa em história da educação em Moçambique.

Moçambique alcançou sua independência em 1975. No entanto, seu Sistema Nacional de Educação (SNE) data de 1983, altura em que foi aprovada a Lei no $4 / 83$, de 23 de março. O momento que vai da independência até a aprovação do SNE é designado Período de Organização e estruturação do setor da educação. É nesse período que acirrados debates sobre uma escola primária moçambicana acontecem e importantes decisões são tomadas com vista a transformar a antiga escola colonial na nova escola, baseada no interesse e na realidade dos moçambicanos.

A análise sócio-histórica da escolarização primária em Moçambique foi a ferramenta que possibilitou a compreensão dos fundamentos que estiveram na base da definição do que deveria ser uma escola primária moçambicana, idealizada para nova nação independente. Essa perspectiva de análise, desenvolvida na Europa, nas décadas de 1960 e 1970, fornece bases para analisar os processos de escolarização a partir das interfaces da sociologia e da história ${ }^{2}$. Nesse sentido, foi a partir das análises das transformações que foram acontecendo noutras componentes do sistema social, nomeadamente na política e na economia que se tornou possível e, de forma mais clara, compreender não só as transformações que produziram a nova escola primária moçambicana, mas também os fundamentos socioeconômicos e políticos que justificaram o modelo de escolarização primária na época (VINCENT; LAHIRE; THIN, 2001).

Este texto está estruturado em três partes. Na primeira discute-se os conceitos frequentemente usados nas reflexões, como modelo de escolarização e escola primária moçambicana. A segunda parte está reservada à análise da revista Tempo como fonte de pesquisa da história da escolarização nos primeiros anos da independência em Moçambique. Na última parte, apresentam-se os debates nacionais sobre a nova escola moçambicana, que antecederam aprovação da Lei ำ 4/83, de 23 de março, destacando os principais encontros, os locais de reunião, os sujeitos presentes, os temas debatidos e a relevância desses debates na construção da nova escola primária moçambicana.

\section{MODELO DE ESCOLARIZAÇÃO E ESCOLA PRIMÁRIA MOÇAMBICANA: TENTATIVAS DE DEFINIÇÃO}

Definir o que se entende por modelo de escolarização, em uma perspectiva sócio-histórica, supõe perscrutar um imaginário por meio do qual podemos indagar qual foi, no período pós-independência do país, a configuração do ensino primário que respondia aos desafios socioeconômicos e políticos da época? Primeiro, entendemos que o conceito de modelo escolar surge

\footnotetext{
2 Este texto se inspira também na contribuição europeia dos sociólogos franceses Guy Vincent, Bernard Lahire e Daniel Thin, cujo texto foi traduzido por Diana Gonçalves Vidal, como A história e a Teoria da forma escolar (2005).
} 
na Idade Média associado ao significado de meio de informação e de formação das novas gerações, e vai ser objeto de debate em finais do século XIX e princípios do século $\mathrm{XX}$, por especialistas em história, pedagogia e sociologia, como foi o caso de Émile Durkheim. Ele entendia a educação como um meio pelo qual a sociedade prepara as condições da existência dos seus - novas gerações - em uma transmissão de valores, dos adultos sobre as crianças, recorrendo a meios que designa de estados físicos, intelectuais e morais exigidos pela sociedade política em função do meio em que a criança se insere. Ou seja, a "educação é a socialização das crianças" (DURKHEIM, 1972, p. 10) e, por isso devia estar submetida à influência do sistema político vigente em uma determinada sociedade ou simplesmente o Estado, que sob a forma de um fiscal ou um juiz, vem tendo a responsabilidade de proteger e fazer ensinar princípios que, implícita e explicitamente, são comuns a todos, na escola.

A partir de Vincent, Lahire e Thin (2001), em uma lógica centrada na função da escola como espaço de socialização dos cidadãos, entendemos o modelo de escolarização como uma forma social de resposta aos imperativos políticos, sociais e econômicos de uma sociedade e época concretas. É, portanto, neste sentido emprestado de Vincent, Lahire e Thin (2001), de forma social de resposta, que defino modelo de escolarização como uma configuração histórica particular dos sistemas de ensino para realização das práticas de sociabilidade escolar das novas gerações. Nesse sentido, a diversidade de configuração dos sistemas de ensino e das práticas constitutivas da sociabilidade escolar das novas gerações faz surgir o conceito de modelos escolares, o que significa que a forma escolar de educação pode assumir a configuração de vários modelos que se sucedem, mas não impedem a coexistência, ao longo do tempo em uma determinada sociedade.

Se entendermos o modelo de escolarização enquanto produto de construção histórica resultante da combinação de dispositivos científicos, religiosos, políticos e pedagógicos que definiram a modernidade como sociedade da escolarização, então, a configuração dos sistemas de ensino e das práticas constitutivas da sociabilidade escolar das novas gerações serão determinadas sócio-historicamente. Por conseguinte, definimos aqui, por modelo de escolarização, as formas pelas quais uma escola pode ser configurada para levar a cabo missões socialmente construídas (da formação de homem novo, no caso em particular) por meio do ensino.

A escola primária moçambicana a que nos referimos é um espaço idealizado pela direção da Frelimo ${ }^{3}$, cuja

\footnotetext{
${ }^{3}$ Frente de Libertação de Moçambique: partido politico que tem governado Moçambique, desde 1975. Antes de ser proclamado partido politico de orientação socialista, a Frelimo foi um movimento de luta pela independência de Moçambique.
}

função social era a formação de continuadores da revolução, fornecendo-lhes os novos conceitos, as novas concepções, a nova mentalidade, a nova personalidade. Ela é o setor-base da transformação cultural que dará sequência ao processo revolucionário. É, em última análise, um instrumento de divulgação e consolidação da linha política da Frelimo. A escola primária moçambicana constitui-se em "espaços organizados, de educação do homem novo, socialista, que no seu pensamento, mas sobretudo no seu comportamento interioriza os princípios do povo e da revolução, pois, será esse homem que constituirá o socialismo" (GÓMEZ, 1999, p. 307).

A escola é adjetivada moçambicana, primeiro, porque foi pela primeira vez pensada e construída por moçambicanos, para serviros interesses dos moçambicanos; segundo, porque é pensada, estrategicamente, para estar alinhada com os objetivos socioeconômicos e políticos da época. A partir desta apropriação do conceito torna-se possível pesquisar historicamente primeiro: para que finalidades socioeconômicas e políticas da época é que a configuração da escola primária moçambicana visava atender, logo a seguir a independência do País? Em que momento e por quais sujeitos foram realizados os debates sobre os novos modelos de escolarização primária no país?

\section{A REVISTA TEMPO COMO FONTE DE PESQUISA EM HISTÓRIA DA EDUCAÇÃo}

As revistas constituem-se na contemporaneidade, importantes espaços para a busca de informações na construção da história da escolarização de muitas sociedades em tempos determinados. Todavia, essa prática, nem sempre foi considerada apropriada para o trabalho de um historiador. A tradição positivista desencorajava o uso do impresso em pesquisas históricas, por considerá-lo subjetivo e falsificador da verdade. Nessa ordem de ideias, o historiador deveria ter uma visão objetiva dos fatos, pois, considerava-se que os impressos tinham "alta carga de subjetividade na narração dos acontecimentos" (CALONGA, 2012, p. 80). Mas, graças às propostas difundidas pela Escola dos Annales, as pesquisas históricas passaram a estreitar as relações com outras áreas, fato "que contribui para uma renovação teórica das pesquisas e também para a incorporação de novas abordagens teórico "metodológicas" (IVASHITA, 2014, p. 4).

O olhar de revistas como espaços de debate sobre a educação remete-nos ao século XIX, nos Estados Unidos, momento em que a Revista Americana de Educação, editada por Henry Barnard (1811-1900), constituiu um privilegiado espaço de divulgação e debate de variados assuntos que interessavam ao ordenamento da escola 
pública norte-americana e, consequentemente, ao sistema de ensino norte-americano (THURSFIELD, 1945). Outra experiência de exploração desse material, que também nos inspira, é a de Gondra (1997), que analisa o ciclo de vida do primeiro periódico editado pelo poder republicano brasileiro, especializado em questões educacionais - a Revista Pedagógica. O autor localiza, inicialmente, o lugar e o sentido da produção de um discurso pedagógico oficial, isto é, identifica quem foi o responsável pela publicação do periódico e suas motivações, examina a estrutura da revista e os seus objetivos e analisa as estratégias de circulação e o ciclo de vida da revista para, finalmente, tentar perceber traços de continuidade no uso do mecanismo de produção, publicação e circulação de discursos por parte do poder público.

É assim que se decide adentrar no mundo da revista Tempo, enquanto material impresso e fonte de pesquisa sobre a história da educação em Moçambique. Com ela, procuramos ampliar o nicho documental da pesquisa histórica, na tentativa de diversificar as opções em fontes, bem como encontrar aspectos que nos permitam desvendar contradições, consensos e lacunas. Esse exercício tem uma dupla finalidade. Primeiro, visa contribuir na desconstrução do imaginário negativo sobre o uso de certos tipos de fontes. E, segundo, estudar em uma perspectiva histórica, o complexo projeto político de formação da escola moçambicana, considerando as relações sociais em seus consensos e divergências. As razões que justificam essas escolhas são justamente porque tomamos a revista Tempo como espaço investido de potencial historiográfico, capaz de nos ajudar a responder o problema histórico que se coloca, ainda que possa haver diferentes visões sobre um determinado fato (IVASHITA, 2014, p. 8).

A revista Tempo foi um dos principais espaços de debate sobre os rumos da educação na construção da nova nação moçambicana no pós-independência. Sua primeira edição saiu às ruas no dia 20 de setembro de 1970. Foi de periodicidade semanal entre 1970 e 1999, e passou a não ser regular (tendo passado a ser quinzenal, mensal ou mesmo trimestral) a partir de 2000 , com a sua privatização, até 2008 (ano do seu encerramento). Desde a sua criação, a política editorial acompanhou os diferentes períodos sociopolíticos que Moçambique foi experimentando, resultando daí as mudanças na ideologia pela qual a empresa jornalística foi abordando as questões educacionais. Nos primeiros três anos que antecederam a independência (1970-1973), assumiu valores liberais e capitalistas, foi nacionalizada em 1975 e, a partir de 1977, passou a se identificar com o socialismo, de orientação marxista-leninista, que perdurou cerca de sete anos (19771984). De 1985 em diante, sua orientação ideológica passou a ser a neoliberal (ZIMBICO, 2016).
O primeiro período de circulação da revista Tempo vai de 1970 a 2008, momento que se situa o recorte temporal dos debates para construção do que chamamos: escola moçambicana de educação primária. Nesse momento, foram publicadas 1574 edições, cujo número de exemplares por edição variou bastante, tendo começado com 5 mil e, por vezes, atingido os $25 \mathrm{mil}$, sem nunca ter ultrapassado a meta dos 40 mil. De mesma forma, variavam o número de páginas para cada edição, tendo começado com 64 páginas, a revista atingiu $80 \mathrm{em} \mathrm{1973,}$ reduziu para 50 nos anos 1980 , e em 2008, encerrou com 64 páginas.

A revista Tempo é, desde a sua criação, o primeiro periódico ilustrado que aparece em Moçambique, cujas imagens eram captadas por máquinas fotográficas de alta resolução da época e impressas a cores, que permaneceram os mesmos até 2008. A gráfica da empresa - a Tempográfica - possuía a primeira impressora rotativa offset de Moçambique, uma Solna Rp 36, que na época era uma das mais modernas tecnologias disponíveis no mercado. A Tempográfica contava também com uma impressora Solna 132, duas máquinas de composição Intertype, uma máquina fotográfica offset - Kendro, uma máquina de picotar e vincar - Grafolux, tintas ManderKidd, produtos químicos Eidesco, chapas de alumínio Willy-Krauses etc., adquiridas a partir de uma fornecedora, representante das marcas, a Casa Nisa, localizada na capital, antiga Lourenço Marques, atualmente Maputo.

A revista foi de circulação nacional e internacional, distribuída por via terrestre e aérea para outras partes do país e no estrangeiro. Os recursos financeiros que suportavam a continuidade da empresa provinham de vendas avulsas para seus assinantes, que dependendo da via de entrega, pagavam valores diferentes por cada unidade. As entregas por via terrestre podiam ser feitas a qualquer destino dentro do país, na mesma via, os destinos para o exterior inclúam países como África do Sul, Suazilandia, Rodésia e Maláui. As entregas podiam ser feitas por via aérea também, particularmente para assinantes residentes na metrópole e ilhas. Hoje, já quase sem assinantes, ela custa, nas bancas de jornal, o preço de 50,00 meticais, atual moeda de Moçambique, o equivalnte a 2,50 reais, no Brasil.

A estrutura interna da revista sempre foi organizada em textos editoriais, de reportagens e das seções. No entanto, a partir de 1974 o espaço editorial da revista passou a ser o espaço-oportunidade onde a linha editorial opinava sobre Moçambique e seu futuro, incluindo a divulgação de pensamentos sobre uma escola moçambicana. As reportagens, fortemente carregadas de ideologia socialista, versavam sobre a vida cotidiana da nova nação, seu povo, em páginas repletas de imagens fotográficas em um colorido que testemunhava fatos e situações reportadas. 
Era nesses espaços que os debates sobre uma escola moçambicana eram aflorados destacando, na maioria das vezes, os discursos do presidente da República, Samora Moisés Machel.

A carga da nova orientação ideológica foi deveras marcante que fez desaparecer a variedade de temáticas que a revista abordava antes de 1974 . Nesse período anterior a 1974 podiam ser encontradas na revista as seções de: 1) notícias, de âmbito nacional e internacional, intituladas Noticiário Nacional e Internacional, respetivamente; 2) informações específicas para mulheres, em um espaço intitulado "Tempo Mulher", com temas sobre a moda, beleza, cuidados domésticos, educação doméstica dos filhos, entre outros; 3 ) análises de noticiários e reportagens sobre Moçambique ou de interesse para o país, recortadas da imprensa local, da metrópole ou de outras províncias portuguesas no ultramar, em um espaço designado "Imprensa de A a Z". Outras seções já não aparecem de forma regular, sendo estas relacionadas a temas de cultura e sociedade, como a música, desporto, cinema, cultura pop etc.

A partir de 1974 os conteúdos informativos foram substituídos por conteúdos nacionalistas, com destaque para a história de Moçambique, a história da Frelimo e da luta armada, tendo a revista se tornado um instrumento/ dispositivo didático de educação popular, no plano da construção da nova nação e da formação do homem novo e da nova sociedade. Os principais debates sobre os rumos que a educação deveria seguir constam nas publicações que se seguem (Tabela 1):

Tabela 1 - Números da revista Tempo selecionados

\begin{tabular}{ccclc}
\hline Data & Ano & Número & Título & Página \\
\hline $01 / 2$ & 1976 & 78 & $\begin{array}{l}\text { Prioridades para Educação } \\
\text { e Cultura }\end{array}$ & $26-31$ \\
$18 / 4$ & 1976 & 289 & $\begin{array}{l}\text { Ir à Escola: uma conquista } \\
\text { da Revolução I }\end{array}$ & $29-37$ \\
$25 / 4$ & 1976 & 290 & $\begin{array}{l}\text { Ir à Escola: uma conquista } \\
\text { da Revolução II }\end{array}$ & $34-39$ \\
$08 / 3$ & 1977 & 340 & $\begin{array}{l}\text { A propósito do 8 de março } \\
\text { Trajetória do Sistema de } \\
\text { Ensino em Moçambique }\end{array}$ & $26-64$ \\
\hline
\end{tabular}

Fonte: Produzido pelo autor com base no material consultado.

Desde a criação da revista e mesmo depois de 1974, os textos ocupavam duas ou três colunas nas páginas e sempre vinham acompanhados de fotografia colorida, com espaços para caricaturas e outras formas de desenho artístico. A apresentação das matérias de conteúdos editoriais, de reportagens e das seções não se encontrava agrupada em páginas sequenciadas, organizadas pela natureza das matérias. Ao longo da revista, essas matérias encontravam-se dispersas e em páginas não sequenciadas, sendo que cada matéria era separada da outra por meio de páginas de publicidade.

As publicidades eram uma fonte de receita para empresa, principalmente entre 1970 e 1973, onde abundam as páginas dos anúncios publicitários de serviços, produtos e marcas de empresas que atuavam no mercado moçambicano e na metrópole. Entre os anunciantes, apareciam com frequência os bancos e suas agencias, representantes de marcas de viaturas, as companhias aéreas e de seguros e outras empresas particulares.

De 1974 a 1985 há um apagamento desta atividade, as páginas de publicidade ficaram cobertas de histórias da Frelimo, histórias de lutas de libertação nacional e de figuras "heroicas", e de publicitação de campanhas designadas operação-produção, como as machambas ${ }^{4}$ do povo, as fábricas têxteis e outras empresas estatais, a serviço da classe operário-camponesa. De 1986 em diante, volta o liberalismo e as atividades publicitárias retomam o rumo comercial.

\section{A CONSTRUÇÃo DA ESCOLA PRIMÁRIA MOÇAMBICANA NOS ESPAÇOS DA REVISTA TEMPO}

Moçambique é herdeiro de um sistema de ensino primário e colonial desajustado à realidade dos moçambicanos e, ao mesmo tempo, racista e discriminatório. As primeiras experiências de organização do processo de escolarização primária datam do século XIX, por um decreto de 2 de abril de 1845, que configura um ensino dividido em dois níveis (elementar e complementar), hierarquiza os conteúdos por níveis (ler, escrever e contar, para o nível elementar e gramática, desenho, geometria e física prática, para o nível complementar) e separa os alunos por sexo (escolas para meninos e para meninas) (ZIMBICO, 2016, p. 406). Em função das demandas sociopolíticas e econômicas de cada época, foram aprovados e publicados novos instrumentos legais que visavam regular a administração e implementação do ensino primário fazendo surgir novos modelos de escolarização primária em Moçambique.

A partir de 1934, a escolarização primária é feita em dois sistemas de ensino paralelos: o ensino oficial, destinado aos filhos dos colonos ou assimilados, e o ensino para indígenas. Ao ensino para indígenas cabia a tarefa de "elevar gradualmente da vida selvagem à vida civilizada dos povos cultos a população autóctone das províncias ultramarinas" (MAZULA, 1995, p. 79) e era divida em Ensino Primário Rudimentar, o Ensino Profissional e o

\footnotetext{
${ }^{4}$ Palavra de origem swahili (da região oriental de África), usada em Moçambique, para designar um campo de produção agrária.
} 
Ensino Normal, tendo sido abolido em 1964. O Ensino Primário Elementar, para os não indígenas visava "dar à criança os instrumentos fundamentais de todo o saber e as bases de uma cultura geral, preparando-a para a vida social" (ZIMBICO, 2016, p. 332) sendo obrigatório e gratuito para todas as crianças, brancas e assimiladas, dos sete aos treze anos. Em 1941, é aprovado o Regulamento do Ensino Primário Oficial pela portaria n. 4.435 de julho, que confere uma nova configuração ao modelo de ensino primário nas escolas não indígenas (MAZULA, 1995; GÓMEZ, 1999).

Algumas alterações são feitas no sistema de ensino primário e a configuração tem outras características. A portaria n. 15.971 de 31 de março de 1962 aprova o ensino de adaptação para os nativos, cuja finalidade era a de "[...] criar condições para os alunos se servirem suficientemente da lingua portuguesa e adquirir os requisitos indispensáveis para frequentar o ensino primário comum [...]" (CASTIANO; NGOENHA, 2013, p.38). Esse era um ensino de três classes, obrigatório e gratuíto, na qual os alunos entravam com sete anos e terminavam aos doze. No mesmo ano, é aprovado o Diploma Legislativo n. 2.286, que dispõe sobre o Ensino Primário Oficial dizendo que ele é para crianças entre os sete e os doze anos de idade e obrigatório. Enquanto não houve alterações significativas no Ensino Primário Oficial, o Ensino de Adaptação foi substituido pelo Ensino Pré-Primário, com as mesmas finalidades que este anterior.

Ora, essa configuração do sistema de ensino colonial apenas excluía, discriminava e perpetuava a dominação racial dos colonos sobre os nativos. Era então necessário escangalhar aquela escola e construir uma genuinamente moçambicana, era preciso fazer da escola uma base para o povo tomar o poder. É assim que aflora o debate nacional visando responder a necessidade de criar uma Escola Primária Moçambicana concebida como "espaços organizados, de educação do homem novo, socialista que, no seu pensamento, mas sobretudo no seu comportamento, interioriza os princípios do povo e da revolução, pois, será esse homem que constituirá o socialismo (GÓMEZ, 1999, p. 307)".

A construção de uma escola primária moçambicana pressupunha transformações em três níveis diferentes do sistema de ensino anterior: 1) organizacional; 2) das políticas educativas e 3) das propostas paradigmáticas. No primeiro nível, se debatiam as mudanças de caráter operativo-administrativas, relativas à administração da educação, realizadas pelas instituições do Estado. No segundo nível o debate se orientava para a produção de novas leis e normas que garantissem o amparo legal das políticas e suas estratégias de implementação e regulagem do comportamento de seus agentes e o funcionamento das escolas. No terceiro nível se situavam os debates em relação às transformações que deviam ser realizadas nas propostas paradigmáticas e filosófico-pedagógicas da prática educativa na escola (CASTIANO; NGOENHA, 2013, p. 14).

A escola primária moçambicana é resultado de experiências de educação nas zonas libertadas ${ }^{5}$ e construída sob os princípios do marxismo-leninismo. É possível observar a partir da revista Tempo (TEMPOGRÁFICA, 1981, p.26-33) que ela surge como negação a uma escola colonial, cujas primeiras experiências de sua organização estavam regulamentadas pelo Decreto de 1845, que definia o modelo de escolarização primária para as colônias. Observa-se ainda, que o modelo de escolarização primária no período colonial passou por várias transformações, suportados por uma legislação que se adensou a partir do inicio dos anos 1930 e se entendeu até o início da década de 1970 do século XX, no sentido de aprimoramento de um sistema de ensino que cumprisse os objetivos do colonizador.

Uma das primeiras ações do Estado com vista a desmantelar o sistema de ensino colonial e construir o Sistema Nacional de Educação foi, sem dúvidas, a nacionalização do ensino, em 24 de julho de 1975, colocando-o a serviço das massas trabalhadoras, materializando uma decisão da histórica primeira reunião do Conselho de Ministros da República Popular de Moçambique, em cumprimento das orientações do Comitê Central da Frelimo (TEMPOGRÁFICA, 1976a, p. 26). Nesse encontro,

o desenvolvimento de um combate frontal contra o analfabetismo, a ignorância e o obscurantismo, ao nível das largas massas populares, a luta contra o elitismo e o favoritismo, produtos do capitalismo e da forma capitalista de organizar o ensino em benefício dos privilegiados, a preparação de novos professores e a coordenação do ensino com o plano de desenvolvimento nacional foram considerados tarefas prioritárias (op. cit., 1976a, p. 26).

Nesse encontro, organizado sob o lema "prioridades para educação e cultura" foram discutidos os atributos que definiriam uma educação moçambicana, da qual

\footnotetext{
As zonas libertadas constituíram as primeiras zonas livres da administração colonial, durante a luta de libertação nacional, onde o Frente de Libertação de Moçambique conquistava e impunha sua ideologia. Foram uma espécie de laboratório onde "a prática produzia a teoria e essa mesma teoria melhorava a prática". As zonas libertadas são um verdadeiro porão a qual se deve descer para compreender os pressupostos da reorganização das escolas nos novos moldes. E lá, segundo a Tempográfica (1976, p. 28), que se encontram as bases para nova estrutura política e uma estrutura de gestão - reorganização essa que, permitindo a participação conjunta e a todos os níveis dos diversos trabalhadores, nas várias tarefas da vida cotidiana das escolas, lançou as bases para estabelecimento de relações de tipo novo, entre alunos, professores e funcionários e para a transformação da escola.
} 
se espelharia a escola primária moçambicana que se pretendia. Como resultado desse encontro, a educação passa a ocupar o primeiro lugar no plano da Reconstrução Nacional. Ela é o "instrumento de formação de continuadores da Revolução, fornecendo-lhes os novos conceitos, as novas concepções, a nova mentalidade, a nova personalidade" (GÓMEZ, 1999, p. 308).

Os debates desse encontro demonstram com clareza o conhecimento que se possuía do modelo escolar colonial que se queria desmantelar. Tratava-se, segundo a de uma escola capitalista, que fazia "distanciação entre os vários trabalhadores da escola - alunos, professores, funcionários - em extratos pré-estabelecidos, rígidos e antidemocráticos". Essa escola era igualmente caracterizada pelo "individualismo, a competição, o elitismo, a ideia de estudar para adquirir uma posição de privilégio e fugir ao trabalho manual, a separação de escolas e cursos por sexos [...]" (TEMPOGRÁFICA, 1976, p. 28-29). Esses eram os males que deviam ser eliminados da "escola moçambicana" e para isso, visitas aos estabelecimentos de ensino eram frequentemente realizados pelas altas estruturas do Ministério da Educação e Cultura.

Uma dessas visitas é publicada pela revista Tempo (TEMPOGRÁFICA, 1976a) com o título "Ir à escola, uma conquista da revolução I"”, cujo encontro foi realizado em uma escola da Machava, reunindo a ministra da Educação e Cultura, Graça Simbine Machel, professores e outros quadros da educação, e tinha em vista analisar os problemas que se enfrentavam para transformar a escola em uma base para o povo tomar o poder. A ocasião serviu igualmente para fazer o balanço do ano letivo 1974/1975, que foi um teste para medir a eficácia das primeiras experiências dos desafios da construção de uma escola moçambicana. Neste encontro foram discutidos assuntos ligados à gestão escolar e à doutrinação.

Na publicação seguinte (TEMPOGRÁFICA, 1976b, p.34-39), sob o titulo "Ir à escola, uma conquista da revolução II" (uma continuidade do encontro realizado em uma escola da Machava, perto da capital moçambicana), os assuntos discutidos focalizavam questões pedagógicas, designadamente o liberalismo, relações professor-aluno, natureza do trabalho do professor, quantidade e qualidade no ensino, colaboração mútua professores-populações e o conteúdo dos textos. A construção da escola como base para o povo tomar o poder - que era o sentido da escola moçambicana nessa altura, nem sempre foi de consensos, tendo se caracterizado também por divergências e dificuldades, que preocupavam os professores, a quem cabia a tarefa de contribuir no referido projeto, através de soluções que exigissem a busca de consensos entre os sujeitos. De um lado a estrutura diretiva representada no referido encontro pela ministra da
Educação; do outro, os professores, sujeitos ativos que de forma direta intervém no processo de ensino e aprendizagem dos alunos na escola moçambicana ora em construção.

O III Congresso da Frelimo, realizado em 1977 [ano a partir do qual este movimento passou a ser um partido de vanguarda, de ideologia socialista, orientado pelos princípios universais do marxismo-leninismo] representou um importante marco do debate sobre a nova escola primária moçambicana. É a partir desse congresso, por conta de aderência do Estado ao socialismo, que a missão da nova escola primária moçambicana passou a ser "a de fornecer a todos os moçambicanos uma concepção científica e materialista do mundo" (GÓMEZ, 1999, p.307). Como forma de garantir que a escola cumprisse a sua nova missão, o congresso em referência, definiu as "linhas gerais de orientação" do ensino primário moçambicano nas seguintes:

Concentrar os recursos do Estado na consolidação do trabalho já desenvolvido, nomeadamente no que respeita a qualidade de ensino, na formação de professores e na orientação pedagógica; apoiar o programa de extensão de ensino as aldeias comunais recorrendo a mobilização de alunos mais velhos que terminaram a $4 \underline{\underline{a}}$ classe ou graus superiores e que se integraram nas aldeias comunais por um certo período de tempo; fazer corresponder o conteúdo dos programas de ensino as necessidades da produção de modo a que os estudantes possam estar aptos a contribuir para uma melhoria imediata das condições de vida e de produção das populações; reciclar 3.000 professores por ano ate 1980 para a elevação do seu nível políticopedagógico; formar, anualmente, ate 1980, cerca de 300 professores primários com a $6^{\underline{a}}$ classe e o curso de formação pedagógica e criar condições para gradua ate 1980 cerca de 60.000 estudantes com a $4^{a}$ classe (TEMPOGRÁFICA, 1977, p. 53).

Alguns dias após o III Congresso, uma reunião orientada pelo presidente Samora Machel, envolvendo alunos, professores e técnicos da educação, foi realizada com vista a materialização das recomendações emanadas desse encontro. A data 8 de março, ficou registada na história do país, como a referencia de uma geração que abnegadamente militou nas várias frentes sociais a favor da causa da reconstrução Nacional. Sobre a nova escola primária moçambicana, este momento representa o início dos debates sobre a qualidade de ensino, com destaque para as ações de formação continuada de professores, à luz da nova orientação pedagógica. Essa pedagogia tradicional é descrita como uma pedagogia do colonialfascismo e que devia ser banida da escola primária moçambicana. Segundo Samora, essa pedagogia produzia um discurso que afirmava: 
eu sou o professor, tu és o aluno; eu ensino e tu aprendes e nada de críticas ou de perguntas indiscretas. - Por centralismo democrático entende só o centralismo e esquece o democrático e espera dos estudantes a passividade de peças de uma máquina. Para o professor burocrata a obediência do aluno é vista não em termos de disciplina revolucionária interiorizada - mas em termos de respeito absoluto pelo seu estatuto de professor. É a hierarquia elevada ao nível de ideologia (TEMPOGRÁFICA, 1977, p. 61).

Essa denúncia visava chamar atenção à necessidade de correção de certas formas de comportamento do professor, consideradas indesejáveis e que caracterizavam a sua relação com os alunos - sujeitos ativos da aprendizagem, pois se acreditava que só dessa forma era possível criar a escola primária moçambicana, uma escola que formasse o homem novo, agente e continuador da revolução.

Os debates sobre a escola primária moçambicana também visavam o aprimoramento da configuração do novo modelo de escolarização primária que estava sendo ensaiado em Moçambique. Trata-se de um ensino primário unitário, baseado na coeducação, reajustado pela Portaria no 24/76, de 29 de janeiro, que fixou novos limites máximos de idade para ingresso no ensino primário: 14 anos para $1^{\underline{a}}$ classe, 15 anos para $2^{\underline{a}}$ classe, 16 anos para $3^{\underline{a}}$ classe, 17 anos para $4^{\underline{a}}$ classe, 18 anos para $5^{\underline{a}}$ classe e 19 anos para $6^{\mathrm{a}}$ classe. Os períodos escolares foram fixados de acordo com a realidade moçambicana e começavam em 1 de janeiro e terminavam em 31 de dezembro, e foram subdivididos em três períodos: $\left.1^{\circ}\right)$ de 16 de fevereiro a 30 de abril; $2^{\circ}$ ) de 16 de maio a 31 de julho e $3^{\circ}$ ) de 16 de agosto a 31 de outubro. $\mathrm{O}$ ano letivo começava em 16 de fevereiro e terminava a 31 de outubro. Ainda nos termos da referida portaria, os novos prazos de matrícula deviam decorrer de 20 de dezembro a 10 de janeiro.

\section{CONSIDERAÇõES FINAIS}

Este texto buscou fazer uma análise do processo da construção do modelo de escolarização primária em Moçambique, no período 1975 a 1982, tomando a revista Tempo como um espaço de debates sobre o processo de criação do referido modelo, com o qual os moçambicanos efetivamente se identificassem. Ao usarmos a revista Tempo, uma fonte antes excluída, quisemos ampliar a projeção do alcance das fontes de pesquisa que são um autêntico produto de construção histórica, tal como é o modelo escolar que se desenvolve, se impõe e acaba sendo aceito pela sociedade na qual estiver vinculado. Os dados analisados permitem constatar que os textos publicados na revista Tempo desvendam uma profunda manifes- tação de relações de poder entre os sujeitos, através de interesses, contradições, consensos, rupturas e continuidades, que se manifestaram na definição e validação de diferentes modelos escolares, quer do período anterior assim como do posterior à independência de Moçambique.

Com efeito, em uma primeira análise, marca a continuidade, pelo menos nos termos da lei, o fato de a educação ser um direito de todos, ainda que a prática evidenciada pelas taxas de analfabetismo herdadas do aparelho colonial mostre o contrário; porquanto a exclusão era baseada em variáveis como cor, sexo, classe social, religião, entre outros, de acordo com o estatuto que era conferido por lei aos cidadãos de então. Todavia, quer em um assim como outro modelo, o Estado puxou para si o dever de definir os conteúdos e o calendário escolar, entre outras ações, um exercício de permanente afirmação do poder de decisão.

A ruptura, no entanto, é marcada pelo fim do carácter dualista da forma escolar e modelos de formação de professores e objetivos políticos de cada um dos modelos escolares. No referido período, visto que o SNE se fundamentava nos princípios universais do marxismoleninismo e no patrimônio comum da humanidade, era enunciado o forte aparato político e ideológico que se revestia o processo de criação do novo modelo escolar, tendo em vista eliminar as estruturas de opressão e transformar a mentalidade de subserviência nos moçambicanos. Para isso era operacionalizado um aparelho burocrático altamente centralizado; as matérias tinham uma linguagem típica de um regime socialista, com um rígido cunho político e ideológico e uma estrutura altamente verticalizada, de acordo com a administração unitária do SNE.

Proclamada a independência, o novo governo socialista formado pela Frelimo, único representante do povo moçambicano, procurou consolidar o novo Estado dirigido por um sistema político de partido único, cujas primeiras decisões caracterizam a sua intenção de construir uma democracia social. Nesse sentido, devia-se desmantelar o aparelho de Estado herdado, convicta que não era possível utilizar o existente, orientando-o para novos objetivos, a partir da experiência colhida durante o governo de transição e primeiros meses de independência. $\mathrm{Na}$ essência, tratava-se de destruir esse aparelho e substituí-lo por uma estrutura que correspondesse aos interesses da aliança operário-camponesa, e nesse processo a nova escola moçambicana, em construção, constituía um privilegiado espaço para forjar novas mentalidades. Houve profundas reformas como a nacionalização de serviços, incluindo as escolas. A sociedade moçambicana era vista com um Estado de democracia popular em que todas as camadas patrióticas, constituídas pelo homem 
novo, deviam participar na construção de uma nova sociedade, livre da exploração do homem pelo homem, em que o poder pertencesse aos operários e camponeses unidos e dirigidos pela Frelimo e exercido pelos órgãos do poder popular.

Face ao elevado analfabetismo, em 1975, foram feitas campanhas nacionais de alfabetização que visavam reduzir o analfabetismo e conferir habilidades básicas na leitura, escrita e cálculo, com vista à integração dos moçambicanos no projeto de construção de uma nova nação, da qual fazia parte a escola moçambicana - uma escola das massas que substituiria a escola dualizada, típica do período colonial. Regulada a participação no sistema de ensino em construção, "a ligação escola-comunidade passou a ser feita e controlada por estruturas e organizações comunitárias de base popular que visavam fazer da escola um centro de vida democrática, prenúncio do centralismo democrático nas escolas" (DOMINGOS, 2015, p. 248). Um dos resultados imediatos é que o ensino diferenciado, em função das aptidões intelectuais individuais, tinha sido abolido e estabelecido um modelo escolar único e uniforme, com ênfase nas reformas massivas e coletivas de ensino, tendentes a equiparar os alunos e produzir cidadãos de certos tipos padronizados. Do ponto de vista sociopolítico, pode-se considerar que esta escola não tenha sido democrática, ao admitir o tratamento igual dos desiguais, no sentido das capacidades intelectuais, o que certamente terá prejudicado o ensino de certo tipo de indivíduos.

\section{REFERÊNCIAS}

CALONGA, Maurilio Dantielly. O Jornal e suas Representações: objeto ou Fonte da História? Comunicação \& Mercado, Dourados, v. 1, n. 2, p. 79-87, nov. 2012. Edição especial. Disponível em: http://www.unigran.br/mercado/ paginas/arquivos/edicoes/1N2/7.pdf. Acesso em: 18 fev. 2017.

CASTIANO, José P.; NGOENHA, Severino. E. A longa marcha duma "Educação para Todos" em Moçambique. 3. ed. Maputo: PubliFix, 2013.

DOMINGOS, Alberto Bive. A educação e as organizações democráticas em Moçambique: experiências da revolução popular. Práxis Educativa, Ponta Grossa, v. 10, n. 1, p.227251, jan./jun. 2015. Disponível em: http://www.revistas2. uepg.br/index.php/praxiseducativa/article/view/6738. Acesso em: 18 fev. 2017.

DURKHEIM, Émile. Educação e Sociologia. Tradução: Lourenço Filho. São Paulo: Melhoramentos, 1972.

GÓMEZ, Miguel Buendia. Educação Moçambicana: história de um processo (1962-1984). Maputo: Universidade Eduardo Mondlane, 1999.
GONDRA, José Gonçalves. O Veículo de Circulação da Pedagogia Oficial da República: a Revista Pedagogica. Revista Brasileira de Estudos Pedagógicos, v. 78, n. 188/189/190, p. 374-395, jan./dez. 1997. Disponível em: http://rbep.inep.gov.br/index.php/rbep/article/view/1061/1035. Acesso em: 18 fev. 2017.

IVASHITA, Simone Burioli. Fontes para a história da educação: a importância dos arquivos. In: REUNIÃO CIENTÍFICA DA ANPED - ANPED SUL, 10., 2014, Florianópolis. Anais [...]. Florianópolis: ANPED, 2014. [p. 1-18]. Disponível em: http://xanpedsul.faed.udesc.br/ arq pdf/144-0.pdf. Acesso em: 18 fev. 2017.

MAZULA, Brazão. Educação, Cultura e Ideologia em Moçambique: 1975-1985. Lisboa: Afrontamento \& Fundo Bibliográfico de Língua Portuguesa, 1995.

SANTANA, Jacimara Souza. A Participação das mulheres na Luta de Libertação Nacional de Moçambique em Notícias (Revista Tempo 1975-1985). Sankofa: Revista de História da África e de estudos da diáspora africana, n. 4, p. 67-87, dez. 2009. Disponível em: http://www.revistas.usp.br/sankofa/ article/viewFile/88746/91642. Acesso em: 18 fev. 2017.

TEMPOGRÁFICA. A propósito do 8 de março. Tempo, Maputo, n. 340, p. 60-64, 8 mar. 1977. Semanal.

TEMPOGRÁFICA. Ir à escola, uma conquista da revolução I. Tempo, Maputo, n. 289, p.28-37, 8 abr. 1976a. Semanal.

TEMPOGRÁFICA. Ir à escola, uma conquista da Revolução II. Tempo, Maputo, n. 290, p. 34-39, 25 abr. 1976b. Semanal.

TEMPOGRÁFICA. Prioridades para Educação e Cultura. Tempo, Maputo, n. 78, p. 26-31, 1 fev. 1976. Semanal

TEMPOGRÁFICA. Trajetória do Sistema de Ensino em Moçambique. Tempo, Maputo, n. 563, p. 26-33. Semanal.

THURSFIELD, Richard Emmos. Henry Barnard's American Journal of Education. Baltimore: The Johns Hopkins University Press, 1945.

VINCENT, Guy; LAHIRE, Bernard; THIN, Daniel. Sobre a história e a teoria da forma escolar. Educação em Revista, Belo Horizonte, v. 1, n. 33, p. 7-47, jun. 2001. Disponível em: http://www.piraquara.pr.gov.br/aprefeitura/secretariaseorgaos/ educacao/uploadAddress/Sobre_a_histu00F3ria_e_a_teoria da_forma_escolar $\% 5 \mathrm{~B} 1273 \% 5 \overline{\mathrm{D}}$. $\mathrm{pdf}$. Acesso em: $18 \mathrm{fev}$. $20 \overline{17}$.

ZIMBICO, Octávio José. Morre a Tribo e nasce a Nação? Política, Administração e História do Ensino Primário em Moçambique. 2016. 409f. Tese (Doutorado em Educação) - Faculdade de Educação, Universidade do Estado do Rio de Janeiro, Rio de Janeiro. 2016. Disponível em: https:// docplayer.com.br/78231880-Universidade-do-estado-do-riode-janeiro-centro-de-educacao-e-humanidades-faculdade-deeducacao-octavio-jose-zimbico.html. Acesso em: 24 set. 2017. 
Recebido em: 24/9/2017.

Aprovado em: 11/12/2018.

Publicado em: 30/4/2019.

Endereço para correspondência:

Octavio Jose Zimbico

Universidade Eduardo Mondlane

Faculdade de Educação

Campus Universitário Principal

Av. Julius Nyerere, 3453

Maputo, Moçambique

\section{Autor:}

Octavio Jose Zimbico

Doutor em Educação pela Universidade do Estado do Rio de Janeiro e Docente

da Universidade Eduardo Mondlane - Moçambique.

Orcid: http://orcid.org/0000-0002-7061-1582

E-mail: o.zimbico@gmail.com. 